\title{
Lipid peroxidation and total radical-trapping potential of the lungs of rats submitted to chronic and sub-chronic stress
}

R.L. Torres ${ }^{2,3}$, I.L.S. Torres ${ }^{1}$, G.D. Gamaro ${ }^{1}$, F.U. Fontella ${ }^{2,3}$, P.P. Silveira ${ }^{1}$, J.S.R. Moreira ${ }^{1}$, M. Lacerda' ${ }^{1}$ J.R. Amoretti ${ }^{1}$, D. Rech ${ }^{1}$, C. Dalmaz ${ }^{1}$ and A.A. Belló ${ }^{2}$

\author{
Departamentos de ${ }^{1}$ Bioquímica and ${ }^{2}$ Fisiologia, Instituto de Ciências Básicas da Saúde, \\ Universidade Federal do Rio Grande do Sul, Porto Alegre, RS, Brasil \\ ${ }^{3}$ Hospital Geral de Porto Alegre, Porto Alegre, RS, Brasil
}

\author{
Correspondence \\ C. Dalmaz \\ Departamento de Bioquímica \\ ICBS, UFRGS \\ Rua Ramiro Barcelos, 2600 \\ Anexo, Laboratório 32 \\ 90035-003 Porto Alegre, RS \\ Brasil \\ Fax: +55-51-3316-5540 \\ E-mail: cdalmaz@ufrgs.br \\ Research supported by PRONEX, \\ CNPq and FAPERGS \\ $\ldots \ldots \ldots \ldots \ldots \ldots$
}

Received February 11, 2003 Accepted September 23, 2003 $\ldots \ldots \ldots \ldots \ldots \ldots \ldots$

\begin{abstract}
Exposure to stress induces a cluster of physiological and behavioral changes in an effort to maintain the homeostasis of the organism. Long-term exposure to stress, however, has detrimental effects on several cell functions such as the impairment of antioxidant defenses leading to oxidative damage. Oxidative stress is a central feature of many diseases. The lungs are particularly susceptible to lesions by free radicals and pulmonary antioxidant defenses are extensively distributed and include both enzymatic and non-enzymatic systems. The aim of the present study was to determine lipid peroxidation and total radical-trapping potential (TRAP) changes in lungs of rats submitted to different models of chronic stress. Adult male Wistar rats weighing 180-230 g were submitted to different stressors (variable stress, $\mathrm{N}=7$ ) or repeated restraint stress for $15(\mathrm{~N}=10)$ or 40 days $(\mathrm{N}=6)$ and compared to control groups ( $\mathrm{N}=10$ each). Lipid peroxidation levels were assessed by thiobarbituric acid reactive substances (TBARS), and TRAP was measured by the decrease in luminescence using the 22'-azo-bis(2-amidinopropane)-luminol system. Chronic variable stress induced a $51 \%$ increase in oxidative stress in lungs (control group: $0.037 \pm 0.002$; variable stress: $0.056 \pm 0.007, \mathrm{P}<0.01$ ). No difference in TBARS was observed after chronic restraint stress, but a significant $57 \%$ increase in TRAP was presented by the group repeatedly restrained for 15 days (control group: $2.48 \pm 0.42$; stressed: $3.65 \pm 0.16$, $\mathrm{P}<0.05)$. We conclude that different stressors induce different effects on the oxidative status of the organism.
\end{abstract}

Key words

- Stress

- TBARS

- TRAP

- Free radicals

- Lungs

- Oxidative stress

\section{Introduction}

Toxic free radicals have been implicated as important pathologic factors in cardiovascular diseases, pulmonary diseases, autoim- mune diseases, inherited metabolic disorders, cancer, and aging (1-4). Oxidative stress arises when the balance between pro-oxidants and antioxidants is shifted toward the pro-oxidants (5). 
The lungs and the pulmonary vasculature are potentially at high risk of injury mediated by oxygen-derived free radicals and lipid peroxidation free radicals (6). There are at least two reasons for this: i) the lung tissue contains unsaturated fatty acids, which are a substrate for lipid peroxidation, and ii) lungs are exposed to higher oxygen concentrations than any other organ in the body (6). Pulmonary antioxidant defenses are widely distributed and include both enzymatic and nonenzymatic systems. In normal individuals, the level of lipid peroxidation in the lungs is very low because of the powerful antioxidant system. Under certain conditions, the antioxidant reserve can be depleted. In such cases, peroxidation of membrane lipids seems to be an unavoidable process in tissue injury (7).

It has been shown that exposure to stress situations can stimulate numerous pathways leading to increased production of free radicals (8-11). It is well known that free radicals generate a cascade, producing lipid peroxidation, protein oxidation, DNA damage and cell death, and contribute to the occurrence of pathological conditions $(8,9)$. Stress may also impair antioxidant defenses, leading to oxidative damage, by changing the balance between oxidant and antioxidant factors $(12,13)$. Both immobilization and variable stress are followed by an increase in lipid peroxidation, measured in plasma and in brain structures (12-14). In addition, decreased activities of the antioxidant enzymes have been observed in the brain of rats treated with glucocorticoids (steroid hormones released by the adrenals in response to physical and psychological stressors) (15), and exposure to physiological levels of these hormones exacerbates reactive oxygen species (ROS) generation (14).

In the present study, we determined the effect of chronic variable and repeated restraint stress (chronic and sub-chronic intensive stress) on total radical-trapping potential (TRAP), and on lipoperoxidation, as- sessed by thiobarbituric acid reactive substances (TBARS), in rat lungs.

\section{Material and Methods}

\section{Animals}

Seventy-four experimentally naive adult male Wistar rats (60 days old; 180-230 g body mass) were used. They were housed in groups of five in Plexiglas cages ( 65 x 25 x $15 \mathrm{~cm}$ ) with the floor covered with sawdust. Animals were maintained in a controlled environment (12-h light/dark cycle, temperature of $22 \pm 2^{\circ} \mathrm{C}$ ) before and throughout the experimental period. Rats had free access to food (standard lab rat chow) and water, except during the period when food or water deprivation was applied. All animal procedures were approved by the institutional Research Committee.

\section{Chronic stress procedures}

The animals were divided into three groups: restraint stress $(\mathrm{N}=6)$, variable stress $(\mathrm{N}=7)$ and control $(\mathrm{N}=10)$. Control animals were maintained undisturbed in their homecages.

Chronic restraint stress model. The restraint-stressed group was taken to a different room, where restraint was carried out by placing the animal in a $25 \times 7 \mathrm{~cm}$ plastic bottle, adjusting it with plaster tape on the outside, so that the animal was unable to move. There was a $1-\mathrm{cm}$ hole at one end for breathing. The animals were stressed $1 \mathrm{~h} /$ day, 5 days a week for 40 days (16). The immobilization procedure was performed between 10:00 and 12:00 h.

Chronic variable stress model. A 40-day variable-stressor paradigm (17) was used for the animals in the stressed group (14). The following stressors were used: a) $24 \mathrm{~h}$ of food deprivation; b) $24 \mathrm{~h}$ of water deprivation; c) 1 to $3 \mathrm{~h}$ of restraint, as described above; d) 1 to $3 \mathrm{~h}$ of restraint at $4^{\circ} \mathrm{C}$; e) forced 
swimming for 10 or $15 \mathrm{~min}$, as described below; f) a flashing light for 60 to $240 \mathrm{~min}$, as described below, and g) isolation. Forced swimming was carried out by placing the animal in a glass tank measuring $50 \times 47 \times 40$ $\mathrm{cm}$, with $30 \mathrm{~cm}$ of water at $23 \pm 2^{\circ} \mathrm{C}$. Exposure to a flashing light was performed by placing the animal in a $50-\mathrm{cm}$ high, $40 \times 60$ $\mathrm{cm}$ open field made of brown plywood with a frontal glass wall. A 40-W lamp flashing at a frequency of 60 flashes per minute was used (Table 1).

\section{Sub-chronic intensive stress procedure}

The animals were stressed by restraint as described above for $150 \mathrm{~min}$ daily for 15 days (adapted from Ref. 18). Control animals were kept undisturbed in their homecages. The stress was applied to the animals in a different room. The immobilization procedure was carried out between 10:00 and $14: 00 \mathrm{~h}$

\section{Sample preparation}

Animals were killed by decapitation $24 \mathrm{~h}$ after the last exposure to stress and their lungs were removed and frozen by immersion in liquid nitrogen. Samples were stored at $-70^{\circ} \mathrm{C}$ until analysis. The lungs were homogenized 1:5 (w:v) in ice-cold $0.1 \mathrm{M}$ phosphate buffer, $\mathrm{pH} 7.4$, and the homogenates were centrifuged at $900 \mathrm{~g}$ to remove the particulate fraction. The supernatant was used to assay TBARS, TRAP, and protein content. Protein was determined by the method of Lowry et al. (19) bovine serum albumin as standard.

\section{TBARS determination}

Lipid peroxidation was assessed by measuring TBARS concentration by a spectrophotometric method (14,20-22). Samples $(250 \mu \mathrm{l})$ were deproteinized with $500 \mu \mathrm{l}$ $10 \%$ trichloroacetic acid and centrifuged at
$900 \mathrm{~g}$ for $10 \mathrm{~min}$. The supernatant was mixed with $750 \mu 1$ of $0.67 \%$ TBARS. The mixture was heated for $15 \mathrm{~min}$ in a boiling water bath, and then cooled. The organic phase containing a pink chromogen was extracted with $750 \mu l$ of $n$-butanol and used to meas-

\begin{tabular}{|c|c|c|}
\hline $\begin{array}{l}\text { Day of } \\
\text { treatment }\end{array}$ & Stressor used & Duration \\
\hline 1 & Water deprivation & $24 \mathrm{~h}$ \\
\hline 2 & Food deprivation & $24 \mathrm{~h}$ \\
\hline 3 & Isolation & $24 \mathrm{~h}$ \\
\hline 4 & Isolation & $24 \mathrm{~h}$ \\
\hline 5 & Isolation & $24 \mathrm{~h}$ \\
\hline 6 & Flashing light & $3 h$ \\
\hline 7 & Food deprivation & $24 \mathrm{~h}$ \\
\hline 8 & Forced swimming & $10 \mathrm{~min}$ \\
\hline 9 & Restraint & $1 \mathrm{~h}$ \\
\hline 10 & Water deprivation & $24 \mathrm{~h}$ \\
\hline 11 & No stressor applied & - \\
\hline 12 & No stressor applied & - \\
\hline 13 & Restraint + cold & $2 \mathrm{~h}$ \\
\hline 14 & Flashing light & $2.5 \mathrm{~h}$ \\
\hline 15 & Food deprivation & $24 \mathrm{~h}$ \\
\hline 16 & Forced swimming & $15 \mathrm{~min}$ \\
\hline 17 & Isolation & $24 \mathrm{~h}$ \\
\hline 18 & Isolation & $24 \mathrm{~h}$ \\
\hline 19 & Isolation & $24 \mathrm{~h}$ \\
\hline 20 & Water deprivation & $24 \mathrm{~h}$ \\
\hline 21 & Food deprivation & $24 \mathrm{~h}$ \\
\hline 22 & Flashing light & $3 h$ \\
\hline 23 & Restraint & $2 \mathrm{~h}$ \\
\hline 24 & Isolation & $24 \mathrm{~h}$ \\
\hline 25 & Isolation & $24 \mathrm{~h}$ \\
\hline 26 & Restraint + cold & $1.5 \mathrm{~h}$ \\
\hline 27 & Forced swimming & $10 \mathrm{~min}$ \\
\hline 28 & Flashing light & $3.5 \mathrm{~h}$ \\
\hline 29 & No stressor applied & - \\
\hline 30 & Food deprivation & $24 \mathrm{~h}$ \\
\hline 31 & Restraint & $3 \mathrm{~h}$ \\
\hline 32 & Flashing light & $2 \mathrm{~h}$ \\
\hline 33 & Water deprivation & $24 \mathrm{~h}$ \\
\hline 34 & Restraint + cold & $2 \mathrm{~h}$ \\
\hline 35 & Forced swimming & $15 \mathrm{~min}$ \\
\hline 36 & Isolation & $24 \mathrm{~h}$ \\
\hline 37 & Isolation & $24 \mathrm{~h}$ \\
\hline 38 & No stressor applied & - \\
\hline 39 & Flashing light & $3 \mathrm{~h}$ \\
\hline 40 & Forced swimming & $10 \mathrm{~min}$ \\
\hline
\end{tabular}

The stressors were applied to all animals in the variable stress group. Intact controls were undisturbed in their homecages during the 40 days of treatment. 
ure absorbance at $535 \mathrm{~nm}$ with a Beckman Spectrophotometer (model DU 640, Fullerton, CA, USA). TBARS levels are represented as malondialdehyde equivalents/mg protein and reported as percentage of control.

\section{TRAP determination}

The TRAP represents the total antioxidant capacity of the tissue and was determined by measuring the luminol chemiluminescence intensity induced by thermolysis of 2-2'-azo-bis(2-amidinopropane) dihydro-

Figure 1. Effect of exposure to two different models of chronic stress on TBARS (A) and TRAP (B) levels in rat lungs. TBARS are reported as mean \pm SEM, considering the control group to be equal to 100 ( $N=5-10 /$ group). TRAP is reported as mean \pm SEM equivalents in nmol Trolox/mg protein $(\mathrm{N}=7$ 10/group). TBARS $=$ thiobarbituric acid reactive substances; TRAP $=$ total radical-trapping potential. ${ }^{*} P<0.01$ compared to the other groups (one-way ANOVA, followed by the Student-Newman-Keuls test). There was no significant difference in TRAP levels between groups (one-way ANOVA; $P$ > 0.05).

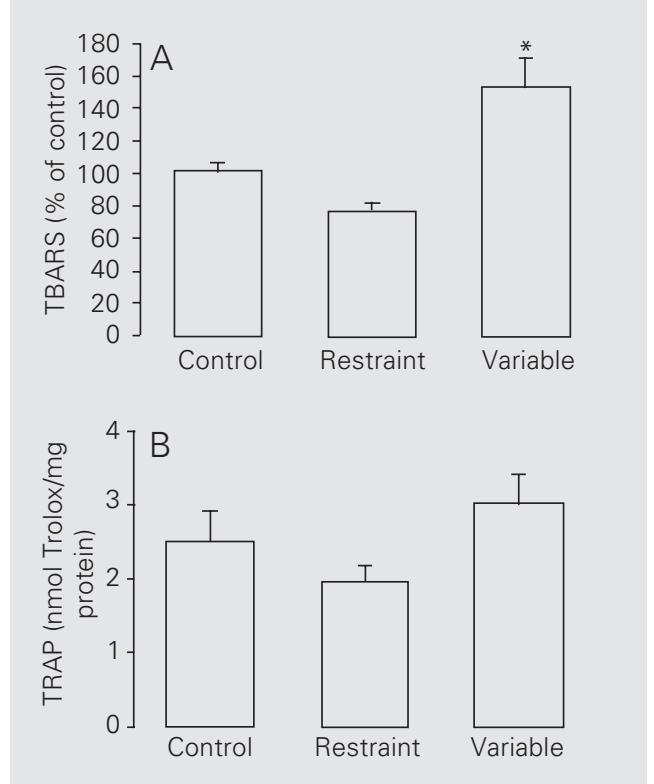

Table 2. TBARS and TRAP results for the two experiments (two models of chronic stress and sub-chronic stress).

\begin{tabular}{lll}
\hline & \multicolumn{1}{c}{ TBARS } & \multicolumn{1}{c}{ TRAP } \\
\hline Control group (Experiment 1) & $0.037 \pm 0.002(10)$ & $2.48 \pm 0.42(10)$ \\
Variable chronic stress & $0.056 \pm 0.007^{*}(5)$ & $2.99 \pm 0.42(7)$ \\
Restraint chronic stress & $0.028 \pm 0.002(5)$ & $1.93 \pm 0.23(6)$ \\
Control group (Experiment 2) & $0.058 \pm 0.010(7)$ & $2.32 \pm 0.25(10)$ \\
Sub-chronic intensive stress & $0.065 \pm 0.011(8)$ & $3.65 \pm 0.16^{*}(6)$
\end{tabular}

TBARS are reported as mean \pm SEM (nmol of malondialdehyde/mg of protein). TRAP is reported as mean \pm SEM equivalents in nmol Trolox/mg protein. The number of animals is given in parentheses. TBARS $=$ thiobarbituric acid reactive substances; TRAP $=$ total radical-trapping potential. ${ }^{*} P<0.05$ compared to the respective control group (one-way ANOVA, followed by the Student-Newman-Keuls test for chronic procedures; Student $t$-test for sub-chronic procedures). chloride (ABAP) $(2,3,14,23,24)$. The background chemiluminescence was measured using $4000 \mu 1$ of $10 \mathrm{mM}$ ABAP and $10 \mu 1$ of $4 \mathrm{mM}$ luminol, both in $100 \mathrm{mM}$ glycine buffer, $\mathrm{pH}$ 8.6. The addition of $10 \mu \mathrm{l}$ of 80 $\mu \mathrm{M}$ Trolox (hydrosoluble vitamin E) or 10 $\mu 1$ of tissue homogenate (diluted 1:4) to the incubation medium reduces chemiluminescence. The time necessary to return to the levels observed before the addition was considered to be the induction time. Induction time is directly proportional to the antioxidant capacity of the tissue $(2,3,14,23,24)$ and was compared to the induction time of Trolox. Results are reported as Trolox units/ $\mathrm{mg}$ protein. One unit is defined as the amount of antioxidant equivalent to $1 \mathrm{mM}$ Trolox.

\section{Statistical analysis}

Data are reported as means \pm SEM and were analyzed by one-way ANOVA followed by the Student-Newman-Keuls test (experiment 1) or by the Student $t$-test (experiment 2) (25).

\section{Results}

\section{Effect of chronic stress on TBARS levels and TRAP in rat lungs}

In this experiment, two models of chronic stress were used, i.e., repeated restraint and variable stress, both for a period of 40 days. There were significantly higher TBARS levels in the lungs of rats chronically stressed using the variable model when compared to the other two groups (control and chronic restraint stress; Figure 1A; $\mathrm{P}<0.01)$. We found no difference in total antioxidant pulmonary capacity between groups $(\mathrm{P}>0.05$; Figure 1B; see also Table 2).

Effect of sub-chronic intensive stress (15 days) on TBARS levels and TRAP in rat lungs

In this experiment, a short period of treat- 
ment was used (15 days), but restraint was applied using a more intensive schedule (2.5 $\mathrm{h} /$ day). TRAP was significantly higher in the stressed group than in the control group $(\mathrm{P}<$ 0.05 ; Figure $2 \mathrm{~B}$ ). No significant difference was observed in pulmonary lipid peroxidation, as assessed by TBARS, between the sub-chronic intensively stressed group and control group $(\mathrm{P}>0.05$; Figure $2 \mathrm{~A}$; see also Table 2).

\section{Discussion}

In the current experiments, we used the TBARS assay to evaluate lipid peroxidation in rat lungs exposed to different models of chronic stress. This assay is the easiest method used to study the effects of different treatments on lipid peroxidation and can be applied to crude biological extracts. Although its specificity has been questioned (26), this particular assay is widely used for ex vivo and in vitro measurements $(2,3,21,22,27,28)$ and is accepted as an empirical window for the examination of the complex process of lipid peroxidation (26).

In contrast, the TRAP assay was developed to measure the total radical trapping potential of biological samples. This test measures both non-enzymatic antioxidants, such as glutathione, ascorbic acid, $\alpha$-tocopherol, $\beta$-carotene, as well as the antioxidant potential resulting from enzymatic action $(12,23)$. Measurement of all these antioxidants is essential for assessing antioxidant status. However, the number of different antioxidants in biological samples makes it difficult to measure each separately. Furthermore, the possible interaction between different antioxidants may also make the measurement of individual antioxidants less representative of the overall antioxidant status (23). Methods to evaluate the total antioxidant potential were therefore developed for the reasons described above. The TRAP assay employed in the current study is widely used $(1-3,12,23)$ and is based on the prin- ciple that the production of peroxyl radicals from ABAP oxidizes luminol, leading to the formation of luminol radicals that emit light (23). Antioxidants present in the sample determine a reduction in this chemiluminescence. The time necessary to return to the levels observed before the addition is directly proportional to the antioxidant capacity of the tissue $(14,23)$. This type of determination is useful since it provides information regarding the evaluation of the capacity of a biological fluid to prevent the damage associated with free radical processes.

In the present study, we showed that chronic variable stress induced a significant increase in TBARS levels in rat lungs compared to the restraint chronic stress and control groups. Conversely, sub-chronic intensive treatment did not significantly alter TBARS levels compared to control. In addition, no differences in TRAP were observed in the lungs of rats chronically stressed by immobilization, or by variable stressors, in either of the chronic models applied for a period of 40 days. The animals submitted to sub-chronic intensive treatment, however, demonstrated a significantly higher TRAP in lungs compared to control.
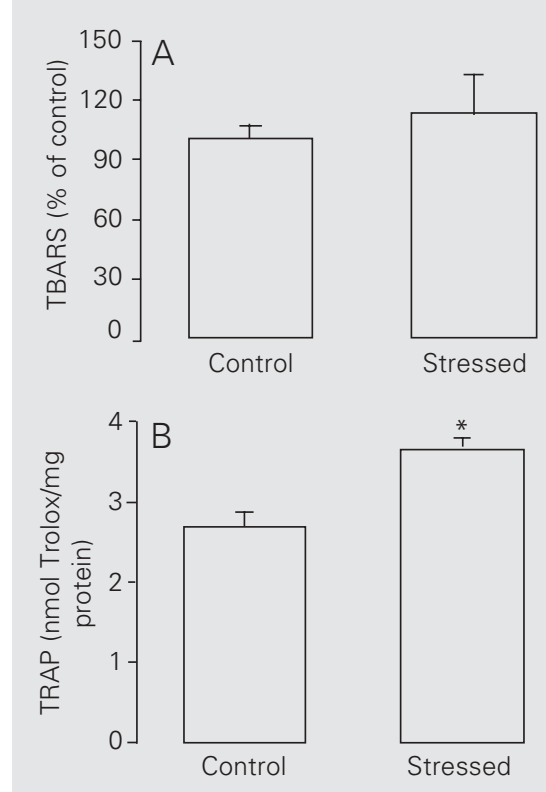

Figure 2. Effect of exposure to sub-chronic intensive stress (15 days) on TBARS (A) and TRAP (B) levels in rat lungs. TBARS are reported as mean \pm SEM, considering the control group to be equal to $100(\mathrm{~N}=5-10 /$ group). TRAP is reported as mean \pm SEM equivalents in nmol Trolox/mg protein $(\mathrm{N}=6$ 10/group). For abbreviations, see legend to Figure 1. There was no significant difference in TBARS levels between groups (Student $t$-test). ${ }^{*} P<0.05 \mathrm{com}$ pared to the control group (Student $t$-test). 
The mechanisms by which animals exposed to sub-chronic stress present increased total antioxidant potential are not clear. TRAP measurement constitutes a useful index of the capacity of a compound, or fluid, to modulate the damage associated with an enhanced production of free radicals (1). In addition, studies of total antioxidant potential have been suggested to be useful for detecting and monitoring environmental damage and for clinical follow-up, in addition to aiding the development of therapies with anti-free radical action (29). We believe that the measurement of individual antioxidants may be an interesting step to further identify the mechanisms involved in these effects.

While immobilization stress or exposure to glucocorticoids may lead to increasing ROS production $(15,30)$, exposure to chronic stress may induce regulatory changes in glucocorticoid release, or their receptors (31). It should be noted that in the chronic restraint stress model the increase in corticosterone levels after exposure to stress for 40 days is much lower than after the first stress session (32). In the present study, we chose to use variable chronic stress in order to reduce the predictability of treatment, which may occur with repeated exposure to the same stressor. Therefore, stressors were applied in different schedules each day. Moreover, in the variable stress model, animals were exposed both to emotional and physical stressors (e.g., forced swimming for 10 or $15 \mathrm{~min}$ ). These different stressors may induce different effects on the oxidative status of the organism and, probably, the results observed represent the sum of the effects of all different stressors. For example, it is known that exhaustive exercise enhances oxygen utilization, which may help to explain the increase in lipoperoxidation observed only in this variable chronic stress model (33). In addition, other situations used as stressors in this model, such as food or water deprivation, could lead to metabolic changes that result in an imbalance in the oxidative status. In studies on other tissues, lipoperoxidation has been observed to increase after different stressors, including cold, immobilization and immobilization plus cold. However, alterations in antioxidants vary according to the stressor used (34). Nevertheless, this model represents a good model of chronic stress in animals, including humans, since organisms are exposed to different types of stressors in nature. In addition, it is still possible that the combined effect of different stressors may be different from the individual effect of each stressor.

In the present study, chronic variable stress induced increased oxidative stress in lungs, as demonstrated by increased TBARS without any changes in TRAP. In contrast, a different effect was observed in the response to chronic restraint stress for 15 days (increased TRAP without any changes in TBARS). There were no differences in oxidative stress in animals chronically immobilized for 40 days. These results suggest different vulnerability to oxidative stress in different models of stress. Repeated stress during a relatively short period of time (15 days) may have induced an increased antioxidant potential, which may be a mechanism for the organism to protect itself against ROS generation following exposure to stress. Another study, employing acute stress by immobilization, also observed increased activity of an antioxidant enzyme (glutathione peroxidase) in brain and retina (34). The increase in TRAP observed in the present study is probably enough to keep the steadystate ROS concentration under control, since no change in TBARS was observed during a short period of time (15 days). On the other hand, when exposed for longer periods of time (40 days of restraint), the animals possibly adapt to this stressor, as demonstrated by lower levels of corticosterone when compared to the initial days of treatment $(32,35)$. The possible adaptation to a repeated stressor, with progressively smaller responses to it, may help to explain why variable chronic 
stress, but not repeated-restraint stress, induces lipoperoxidation after 40 days of treatment.

It is important to observe that, although potentially harmful, oxidants are increasingly recognized as pathophysiologic mediators primarily produced by inflammatoryimmune cells as a host defense mechanism, but also by various other cell types as intracellular mediators in various cell responses, thus affecting inflammatory-immune processes or inducing resistance (for a review, see Ref. 36). To provide extracellular antioxidant defense mechanisms, respiratory tract epithelial cells synthesize and secrete several antioxidant enzymes such as extracellular forms of superoxide dismutase $(37,38)$ and glutathione peroxidase (39), as well as several metal-binding proteins (transferrin, ceruloplasmin) that minimize the involvement of transition metal ions (iron, copper) in oxidant reactions (37). Additionally, the extracellular epithelial lining fluids also contain various non-enzymatic antioxidant systems, including vitamin $\mathrm{C}$ (ascorbate), and vitamin E ( $\alpha$-tocopherol) (36).

The increased TBARS levels observed after chronic variable stress in lung homogenates may be a cause of damage to cell membranes, since polyunsaturated fatty acids of the cell membranes may be degraded by this process with consequent disruption of membrane integrity, leading to injury of lung cells or disorders of their function, eventually increasing the injury induced by other diseases. Membrane peroxidation can lead to changes in membrane fluidity and permeability. Differences in defense mechanisms, such as antioxidant levels or repair mechanisms, may play a key role in the manner by which animals respond to these potentially damaging situations.

The present results showed that the pulmonary defense system is effective against TBARS-induced stress when the animal is able to predict it, but unpredictable stressors or possibly physical stressors may lead to increased TBARS levels. Under these conditions, the antioxidant potential was maintained. This increase in TBARS is important since patients with pulmonary disease may be chronically stressed by the disease itself or by environmental factors, and the possibility of increased TBARS may be a factor in these cases. Further investigations are required for a better understanding of this phenomenon.

\section{Acknowledgments}

We thank Dr. Adriane Belló for helpful suggestions.

\section{References}

1. Alho H, Leinonen JS, Erhola M, Lonnrot K \& Acjmelacus R (1998). Assay of antioxidant capacity of human plasma and CSF in aging and disease. Restorative Neurology and Neuroscience, 12: 159165.

2. Pettenuzzo LF, Schuck PF, Wyse AT, Wannmacher CM, Dutra-Filho CS, Netto CA \& Wajner M (2003). Ascorbic acid prevents maze behavioral deficits caused by early postnatal methylmalonic acid administration in the rat. Brain Research, 976: 234-242.

3. Latini A, Scussiato K, Rosa RB, Liesuy S, Bello-Klein A, Dutra-Filho CS \& Wajner M (2003). D-2-Hydroxyglutaric acid induces oxidative stress in cerebral cortex of young rats. European Journal of Neuroscience, 17: 2017-2022.

4. Heffner JA \& Repine JE (1989). State of the art: pulmonary strategies of antioxidant defense. American Review of Respiratory Disease, 140: 531-554.
5. Prior RL \& Cao G (1999). In vivo total antioxidant capacity: Comparison of different analytical methods. Free Radical Biology and Medicine, 27: 1173-1181.

6. Kovacheva S \& Ribarov SR (1995). Lipid peroxidation in lung of rats stressed by immobilization: Effects of vitamin E supplementation. Lungs, 173: 255-263.

7. Di Luzio NR (1973). Antioxidants, lipid peroxidation, and chemicalinduced liver injury. Federation Proceedings, 32: 1875-1881.

8. Liu J, Wang X, Shigenaga MK, Yeo HC, Mori A \& Ames BN (1996). Immobilization stress causes oxidative damage to lipid, protein, and DNA in the brain of rats. FASEB Journal, 10: 1532-1538.

9. Liu J \& Mori A (1999). Stress, ageing and oxidative damage. Neurochemical Research, 24: 1479-1497.

10. Matsumoto K, Yobimoto K, Huong NTT, Abdel-Fattah M, Hien TV \& Watanabe H (1999). Psychological stress-induced enhancement of 
brain lipid peroxidation via nitric oxide systems and its modulation by anxiolytic and anxiogenic drugs in mice. Brain Research, 839: $74-$ 84

11. Olivenza R, Morro MA, Lizasoain I, Lorenzo P, Fernandez AP, Bosca L \& Leza JC (2000). Chronic stress induces the expression of inducible nitric oxide synthase in rat brain cortex. Journal of Neurochemistry, 74: 745-791

12. Liu J, Wang X \& Mori A (1994). Immobilization stress-induced antioxidant defence changes in rat plasma: effect of treatment with reduced glutathione. International Journal of Biochemistry, 26: 511517.

13. Sosnovsky AS \& Kozlov AV (1992). Enhancement of lipid peroxidation in the rat hypothalamus after short-term emotional stress. Bulletin of Experimental Biology and Medicine, 113: 653-655.

14. Manolli L, Gamaro GD, Silveira PP \& Dalmaz C (2000). Effect of chronic variate stress on thiobarbituric-acid reactive species and on total radical-trapping potential in distinct regions of rat brain. Neurochemical Research, 25: 915-921.

15. Mclntosh LJ, Cortopassi KM \& Sapolsky RM (1998). Glucocorticoids may alter antioxidant enzyme capacity in the brain: kainic acid studies. Brain Research, 791: 215-222.

16. Ely DR, Dapper V, Marasca J et al. (1997). Effects of restraint stress on feeding behavior of rats. Physiology and Behavior, 61: 395-398.

17. Katz RJ (1982). Animal model of depression: Pharmacological sensitivity of a hedonic deficit. Pharmacology, Biochemistry, and Behavior, 16: 965-968.

18. Martí O, Marti J \& Armario A (1994). Effects of chronic stress on food intake in rats: influence of stressor intensity and duration of daily exposure. Physiology and Behavior, 55: 747-753.

19. Lowry OH, Rosebrough NJ, Farr AL \& Randall RJ (1951). Protein measurement with the Folin phenol reagent. Journal of Biological Chemistry, 193: 265-275

20. Fontella UF, Pulrolnik V, Gassen E, Wannmacher CMD, Klein AB, Wajner M \& Dutra-Filho CS (2000). Propionic and L-methylmalonic acids induce oxidative stress in brain of young rats. NeuroReport, 11: $541-544$

21. Sener G, Sehirli AÖ, Satiroglu H, Keyer-Uysal M \& Yegen BC (2002). Melatonin improves oxidative organ damage in a rat model of thermal injury. Burns, 28: 419-425.

22. Kaushik S \& Kaur J (2003). Chronic cold exposure affects the antioxidant defense system in various rat tissues. Clinica Chimica Acta, 333: 69-77.

23. Lissi E, Salim-Hanna M, Pascual C \& del Castillo MD (1995). Evaluation of total antioxidant potential (TRAP) and total antioxidant reactivity from luminol-enhanced chemiluminescence measurements. Free Radical Biology and Medicine, 18: 153-158.

24. Tasat DR, Mancuso R, Evelson P, Polo JM, Llesuy S \& Molinari B (2002). Radiation effects on oxidative metabolism in young and aged rat alveolar macrophages. Cellular and Molecular Biology, 48: 529-535.
25. Zar JH (1996). Biostatistical Analysis. 3rd edn. Prentice Hall, Upper Saddle River, NJ, USA.

26. Janero DR (1990). Malondialdehyde and thiobarbituric acid-reactivity as diagnostic indexes of lipid-peroxidation and peroxidative tissue-injury. Free Radical Biology and Medicine, 9: 515-540.

27. Davydov V \& Shvets VN (2001). Lipid peroxidation in the heart of adult and old rats during immobilization stress. Experimental Gerontology, 36: 1155-1160.

28. Tate Jr DJ, Miceli MV \& Newsome DA (1999). Zinc protects against oxidative damage in cultured human retinal pigment epithelial cells. Free Radical Biology and Medicine, 26: 704-713.

29. Lchucher-Michel MP, Lesgards JF, Delubac O, Stocker P, Durand P \& Prost M (2001). Oxidative stress and human disease. Current knowledge and perspectives for prevention. Presse Medicale, 30: 1076-1081.

30. Mclntosh L \& Sapolsky R (1996). Glucocorticoids increase the accumulation of reactive oxygen species and enhance adriamycin-induce toxicity in neuronal culture. Experimental Neurology, 141: 201206.

31. Hermen JP, Adams D \& Prewitt C (1995). Regulatory changes in neuroendocrine stress-integrative circuitry produced by a variable stress paradigm. Neuroendocrinology, 61: 180-190.

32. Torres ILS, Gamaro GD, Silveira-Cucco SN, Michalowski MB, Corrêa JB, Perry MLS \& Dalmaz C (2001). Effect of acute and repeated restraint stress on glucose oxidation to $\mathrm{CO}_{2}$ in hippocampal and cerebral cortex slices. Brazilian Journal of Medical and Biological Research, 34: 111-116.

33. Tsutsumi K, Kusunoki M, Hara T, Okada K, Ohnaka M \& Nakaya $Y$ (2001). Exercise improved accumulation of visceral fat and simultaneously impaired endothelium-dependent relaxation in old rats. Biological and Pharmaceutical Bulletin, 24: 88-91.

34. Yargiçoglu P, Yaras N, Agar A, Gümüslü $S$, Bilmen S \& Özkaya G (2003). The effect of vitamin $E$ on stress-induced changes in visual evoked potentials (VEPs) in rats exposed to different experimental stress models. Acta Ophthalmologica Scandinavica, 81: 181-187.

35. Konarska MR, Stewart E \& McCarty R (1989). Habituation of sympathetic-adrenal medullary responses following exposure to chronic intermittent stress. Physiology and Behavior, 45: 255-261.

36. van der Viet A \& Cross CE (2000). Oxidants, nitrosants, and the lung. American Journal of Medicine, 109: 398-421.

37. Davis WB \& Pacht ER (1997). Extracellular antioxidant defenses. In: Crystal RG, West JB \& Barnes PJ (Editors), The Lung: Scientific Foundations. Raven Press, New York, 2271-2278.

38. Folz RJ, Guan J \& Seldin MF (1997). Mouse extracellular superoxide dismutase: primary structure, tissue-specific gene expression, chromosomal localization, and lung in situ hybridization. American Journal of Respiratory Cell and Molecular Biology, 16: 393-403.

39. Avissar N, Finkelstein JN \& Horowitz S (1996). Extracellular glutathione peroxidase in human lung epithelial lining fluid and in lung. American Journal of Physiology, 14: L173-L182. 